\title{
A Study on Harmonious Rural Tourism Environment Under the Construction of the Socialism New Rural
}

\author{
TANG Boyan ${ }^{1}$ \\ ${ }^{1}$ Tourism and Air Service College, Guizhou Minzu Unversity, Guiyang Guizhou, China
}

\begin{abstract}
Rural environment is the base for the development of rural tourism. At the construction of socialism new rural, the rural tourism environment has been turned to a radical change. The paper analysed from the meaning and the composing of ruroal tourism environment, applyed to discuss the changes and the characcteristics of harmonious rural tourism environment under the construction of socialism new rural, and wish to advance the development of harmonious rural tourism.
\end{abstract}

\section{Introduction}

Several opinions of the CPC Central Committee and the State Council on promoting the construction of a new socialist countryside clearly put forward: Promoting the construction of a new socialist countryside is related to the long-term development of China's agriculture and rural areas, and the overall situation of reform and opening up and modernization. We should give full play to the area polarity of all parties, rely on the hard work of farmers, national support and extensive participation of social forces, and steadily promote the society Socialist new rural construction.

In 2006, the National Tourism Administration determined the "Theme year of rural tourism in China", and made comprehensive arrangements. This is an important measure for the National Tourism Administration and the whole tourism industry to implement the requirements of the Party Central Committee and the State Council on promoting the construction of a new socialist countryside. This is not only a concrete embodiment of promoting "agriculture, rural areas and farmers" with tourism, but also contributes to the construction of a new socialist countryside. The development of rural tourism has brought unprecedented opportunities.

Subsequently, the National Tourism Administration determined the theme of "2007 China's harmonious urban and rural tourism", which further enriched, deepened and extended the connotation of "2006 China Rural Tourism". In order to meet the requirements of the new stage of China's economic and social development, China's tourism industry should, from the height of building a new socialist countryside, further improve the understanding of the significance and role of rural tourism in promoting the construction of new socialist countryside, clarify the responsibilities and tasks of tourism in the construction of new socialist countryside, and actively explore the combination of tourism development and solving the "three rural" problems Suohe innovates the development mode of rural tourism, takes effective measures to speed up the development of rural tourism, promotes the improvement of farmers' income level and cultural quality, speeds up the poverty-stricken area farmers to get rid of poverty and become rich, drives the adjustment of agricultural industrial structure, promotes the rural economic and social development, and promotes the construction of new socialist countryside.

Up to now, rural tourism has been developing vigorously in China, and has made remarkable achievements. The rural economy is booming, and rural tourism has become the main way to get rid of poverty and become rich.

The construction of harmonious rural tourism environment is not only the basic condition of rural tourism development, but also the necessary basis for the sustainable development of rural tourism resources. On the one hand, it is the need of the development of rural communities, on the other hand, it is the basic environment of rural tourism development.

\section{Connotation of rural tourism environment}

\subsection{Definition of rural tourism environment}

At present, scholars at home and abroad hold different views on the definition of rural tourism, but basically agree that "rural" is the basis for attracting tourists to carry out rural tourism, and is the most important symbol to define rural tourism. For the definition of rural tourism environment, we can regard the rural tourism environment as the basic environment of rural tourism development. On the one hand, it is the resource conditions for the development of rural tourism; on the other hand, it is the place environment for rural tourism. 
Based on this, the author defines the rural tourism environment as: the environment centered on rural tourism activities, which refers to the sum of all external conditions for the survival, development of rural tourism activities.

\subsection{The connotation of rural tourism environment}

For the rural tourism environment, we can get the connotation elements of rural tourism environment from the definition.

First, rural tourism environment is the central environment for rural tourism activities. Rural tourism activities are carried out and carried out in the rural tourism environment. Tourists can only experience the "rural" in the rural tourism environment.

Second, the development of rural tourism depends on the rural tourism environment. Rural tourism environment is the primary attraction factor of rural tourism development. "Rural" is the key element that distinguishes "rural tourism" from "urban tourism". The rural tourism environment is the external expression of "rural".

\section{Elements of rural tourism environment}

From the above definition of rural tourism, we can see that rural tourism environment is the environment centered on rural tourism activities and the sum of all external and internal conditions for the survival, development and development of rural tourism activities. Then the elements of rural tourism environment are the sum of all external and internal conditions in the above definition, and these external and internal conditions enable rural tourism activities to survive, carry out and develop. From this point of view, we can regard the rural tourism environment as a whole environmental system composed of four subsystems: rural natural environment, rural social and cultural environment, rural economic environment and rural tourism atmosphere environment. The rural natural environment and rural social and cultural environment are the internal environment of rural tourism, and the rural economic environment and rural tourism atmosphere environment are the external environment of rural tourism.

\subsection{Internal environment of rural tourism}

Rural natural ecological environment and social and cultural environment are not only the resource Attraction Factors in the development of rural tourism, but also the internal environmental factors of rural tourism development. The rural green landscape, rural idyllic scenery and beautiful natural environment can meet the tourists' physiological and psychological needs while meeting the tourists' basic sightseeing needs; the rural social and cultural environment includes tangible social cultural landscape, materialized national customs and intangible rural culture, rural folk customs and unique rural artistic conception environment. At the same time, these environmental factors are also the most attractive elements of rural tourism.

\subsection{External environment of rural tourism}

Rural tourism economic environment and atmosphere environment constitute the external environmental factors of rural tourism.

The economic environment of rural tourism refers to all the economic conditions for tourists to carry out rural tourism activities, including infrastructure conditions, tourism service facilities conditions, tourism investment capacity and tourism investment capacity. If there are tourism enterprises in rural areas, it also includes the policy tendency, management system and employees' understanding and responsibility of rural tourism. The economic environment of rural tourism is the external driving force for the development of rural tourism.

Rural tourism atmosphere environment can be divided into regional rural tourism atmosphere environment, rural community tourism atmosphere environment and rural tourism atmosphere environment created by tourists. Among them, the atmosphere environment of regional rural tourism mainly refers to the environment formed by historical and modern development on the basis of clean and beautiful rural natural environment, reflecting the regional historical and cultural form, local culture or national cultural flavor. The environment of rural community tourism atmosphere mainly refers to a kind of soft environment formed by the views, views and behaviors of rural community residents for rural tourism. This environment is related to the material and economic development of rural communities and the individual development of rural communities. Tourist rural tourism atmosphere environment refers to the tourism quality of rural tourists and the tourism atmosphere reflected by tourists in rural tourism activities. The atmosphere and environment of rural tourism is the first experience of tourists in rural tourism, and it is also the necessary condition to promote the positive development of rural tourism.

The elements of rural tourism environment are shown in Figure 1.

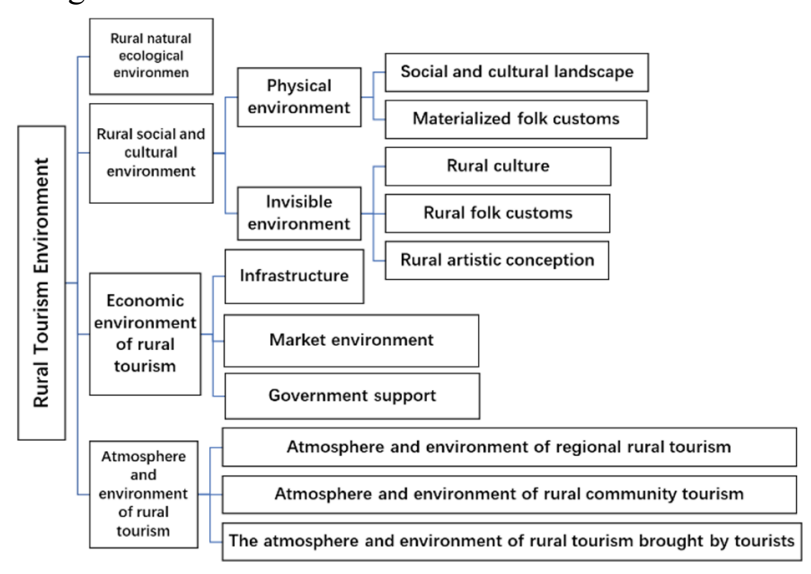

Fig1. Composition of rural tourism environment 


\section{New rural environment in the construction of new socialist countryside}

\subsection{Environmental elements of new socialist countryside}

In China, in order to accelerate the process of socialist modernization, build a well-off society in an all-round way and strive to build a socialist harmonious society, the Fifth Plenary Session of the 16th Central Committee of the Communist Party of China put forward the major strategic task of building a new socialist countryside, and made clear the objectives and requirements of building a new socialist countryside: "production development, rich life, civilized rural style, clean and tidy village appearance, and management of the people Lord ". The goal and requirement of the construction of new socialist countryside has injected new environmental elements into the rural tourism environment.

On the one hand, we can regard it as a part of the environmental factors of the government's political system. On the other hand, under the background of China's specific political system and historical conditions, the proposal of this requirement has a very wide and profound impact on the rural communities in China, which involves the transfer of rural labor force, the adjustment of rural industrial structure, and the income of farmers Based on this, we take the new socialist countryside as a separate environmental element in the rural tourism environment to make a supplement to the rural tourism environment. Thus, the new environment of rural tourism under the background of building a new socialist countryside (as shown in Figure 2).

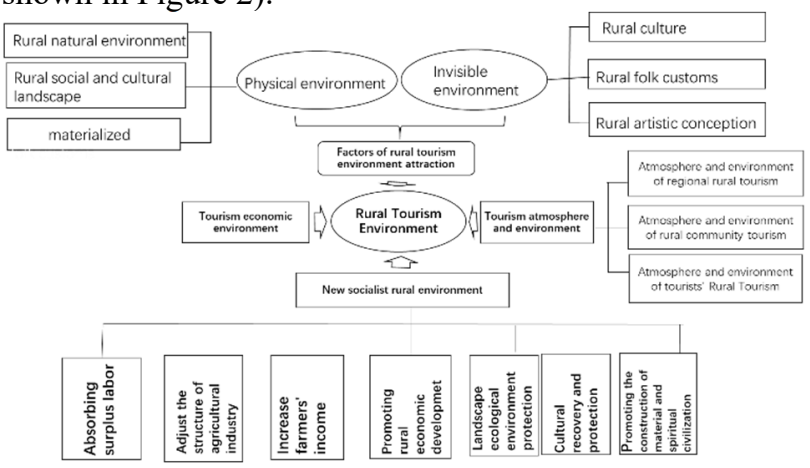

Fig2. the new environment construction mode of rural tourism under the background of new socialist countryside construction

\subsection{The characteristics of rural tourism environment under the background of building a new socialist countryside}

From the analysis of the definition and composition of rural tourism environment, we can see that rural tourism environment is the basic condition for the development of rural tourism. It is the resource condition for rural tourism development and the basic condition for the survival and development of rural community residents. The countryside attracts tourists with its unique environment, and its tourism environment usually shows the particularity different from the general environment.

\subsubsection{The value of rural tourism environmental resources}

We know that the ecological environment is indispensable and useful to human beings, and it is one of the elements of human wealth creation. As a resource, ecological environment has "value or price". Sometimes it is the product value of material, sometimes it is the service value of comfort. Its value is determined by its limitation, scarcity and development and utilization conditions. Once the value of the ecological environment becomes a resource for people to seek benefits, it will become a value that can bring greater value.

On the one hand, the value of rural tourism environmental resources can be directly used in tourism development to seek greater economic benefits for people. Rural tourism environment is a special resource different from urban environment. It attracts many tourists because of its good environmental quality, rich ecological beauty and unique national customs, which also brings more value to the local. On the other hand, the rural environment itself is the living environment for the residents living on this land, and all production and life must be carried out in this environment. Therefore, for the local people, the rural environment is the basis of their survival. Moreover, the relative scarcity of rural tourism environment makes such environmental resources more valuable. In the process of urbanization, many villages which were quiet and remote, with good ecological protection and good environment are gradually involved in the wave of urbanization. With the continuous expansion of the urban fringe, the rural environment in the suburbs of the city has undergone great changes. Many rural urbanization, in this way, makes the rural tourism environment that tourists pursue is scarce. Because of the scarcity of rural environment, the rural tourism environment is more valuable.

\subsubsection{Plasticity of rural tourism environment}

Rural tourism environment is the basic condition for rural tourism activities. Among the four elements of rural environment, the rural tourism natural environment and social and cultural environment are rural original, and the natural environment can be improved and improved. The rural social and cultural environment needs to be maintained and developed, and it is also in constant acculturation and development. The economic environment of rural tourism is the support system of rural tourism development, the construction of infrastructure is plastic, the market and policy are constantly changing, which plays a role in promoting the tourism environment. Among the four elements, the rural tourism atmosphere environment is the most important plastic point. When tourists enter the rural tourism area, the rural atmosphere environment that tourists feel at the first time is the first stop of rural tourists' tourism experience. The tourism atmosphere of rural community is created by the rural natural environment and community ethnic groups. The hot feelings and the strength of "rural" shown by 
community groups are the key elements of tourists' tourism experience. These are the overall image that needs to be shaped in the process of rural tourism development.

\subsubsection{The utilization of rural tourism environment is multi-functional}

Rural tourism environment contains many environmental elements. On the one hand, the beautiful rural natural environment is the attraction factor for tourists to carry out rural tourism, on the other hand, it is also the basic environment for local people to survive. Both tourists and local ethnic groups hope to have a beautiful, peaceful and harmonious rural natural environment. The simple and natural environment in rural areas is a place for tourists to relax themselves. In order to integrate tourists and nature into one, so as to achieve the mental state of freedom, transcendence and liberation, it is necessary to maintain the natural features of the countryside and create a simple, relaxed, independent and far away from the ordinary rural atmosphere for tourists. Rural environment can bring tourists a variety of tourism experience, which is the performance of its multi-function.

\subsubsection{The practicality and experience of rural tourism environment to tourists}

The construction of new socialist countryside has injected new environmental elements into rural tourism. For example, the equal emphasis on material and spiritual civilization in rural areas makes the modern new countryside present a new spiritual outlook, strengthens the rural tourism atmosphere environment, and enables tourists to experience the new customs of new farmers in the new period in the new rural environment. At the same time, the construction of new socialist countryside emphasizes the scientificity, and provides tourists with original rural experience while protecting the rural environment. Such as rural sightseeing and shopping agricultural park, rural rental farm, rural leisure farm, education Agricultural Park, rural club and other tourism projects, which have strong practical and experiential tourism activities for tourists, are the typical representatives of rural environmental utilization in the current new rural construction.

\subsubsection{The duality of rural tourism environmental management}

Rural tourism environmental management is the combination of tourism environmental benefits and agricultural industry economy, which is a complex economy. On the one hand, the countryside uses its beautiful natural environment and cultural environment to attract tourists. On the other hand, agricultural products in rural areas are not only environmental elements, but also tourism products, which can promote the promotion of agricultural products and the development of rural agricultural industry economy.

\section{5 conclusion}

From the perspective of the future development trend of rural tourism, creating a good rural tourism environment has become a good way to improve tourists' tourism experience and enhance their sense of intimacy, participation and experience in rural tourism. Through the integrated construction of rural tourism environment, it can lay a good experience foundation for the future development of rural tourism, thus increasing the attraction of tourism and making the rural culture and rural economy develop continuously.

\section{Reference}

1. Huang Guoqin Rural ecological environment and the construction of new socialist countryside $[\mathrm{J}]$ Journal of Jinggangshan Cadre College, China Vol.2, No.3, Sep. 2006.

2. Ma Dongsheng On the role of rural tourism in the construction of New Countryside [J] Hunan agricultural machinery, 2007.01.

3. Shao Qiwei. Developing rural tourism and promoting the construction of New Countryside. China Forum today, issue 2-3, 2007.

4. Tang Boyan Research on the value accounting of tourism ecological environment resources [J] China's population resources and environment, 2008 issue 5.

5. Wang Jian On the path of building a new socialist countryside [J] innovation. Issue 6, 2007.

6. Wang Suqin The interactive model of rural tourism and the construction of new socialist countryside $[\mathrm{J}]$ Economic Forum 2007.1. 